
\section{Ecturs} Supportive Services, Flinders University, Adelaide, Australia ${ }^{2}$ Division of Medical Oncology, Department of Medicine, Duke University Medical Centre, Durham, North Carolina, USA ${ }^{3}$ Palliative Care Program, Barwon Health, Geelong, Victoria, Australia

\section{Correspondence to} David C Currow, Discipline, Palliative and Supportive Services, Flinders University, Bedford Park, South Australia 5042, Australia; david. currow@flinders.edu.au

Received 20 October 2013 Accepted 22 October 2013 Published Online First

8 November 2013

\title{
The active identification and management of chronic refractory breathlessness is a human right
}

\author{
David C Currow, ${ }^{1}$ Amy P Abernethy, ${ }^{1,2}$ Danielle N Ko ${ }^{3}$
}

\begin{abstract}
Chronic refractory breathlessness is defined as breathlessness at rest or on minimal exertion that will persist chronically despite optimal treatment of the underlying cause(s). At any time, 1\% of the population report a modified Medical Research Council dyspnoea score of $\geq 3$ chronically. Despite the prevalence, severity and chronicity of this symptom and an evidence base of affordable and safe interventions, chronic refractory breathlessness remains grossly undertreated. Many patients and clinicians accept the presence of the chronic refractory breathlessness as an inevitable part of an illness, with no thought of treating the symptom despite an evidence base for its safe treatment. Consensus statements from major respiratory clinician organisations now endorse such a clinical course. Failure to enquire about, assess and properly treat chronic refractory breathlessness with opioids as outlined in specialist clinical guidelines is now an unacceptable level of care ethically and is, arguably, a breach of people's human rights. Adequate pain control through access to pain relief is now accepted as a human right and, given its burden across the world, the symptomatic treatment of chronic refractory breathlessness should be seen in exactly the same way.
\end{abstract}

Chronic refractory breathlessness is defined as breathlessness at rest or on minimal exertion that will persist chronically despite optimal treatment of the underlying cause(s). At any time at least 1\% of the population report a modified Medical Research Council dyspnoea score of 3 (ie, stopping for breath after walking about $100 \mathrm{~m}$ or after a few minutes on level ground) or greater, with one-third of these patients housebound by their breathlessness. ${ }^{1}$ Frequent causes include chronic obstructive pulmonary disease, interstitial lung diseases, heart failure and advanced cancer. Like pain, chronic refractory breathlessness is a debilitating symptom that decreases physical and mental functioning, impairs one's ability to meaningfully interact with and contribute to society ${ }^{2}$ and creates a high emotional, social and economic burden on the patients themselves, their carers and society more broadly. ${ }^{3}$

Despite the prevalence, severity and chronicity of this symptom and an evidence base of affordable and safe interventions, chronic refractory breathlessness remains grossly undertreated. For many patients and clinicians the presence of the symptom is simply accepted as part of the illness, with no thought that the symptom and its impact could and should be specifically assessed and treated. Many patients with chronic refractory breathlessness will silently adapt to its limitations and suffering, omitting to volunteer to health professionals the presence and severity of the breathlessness they experience or the consequent impairment of activities of daily living. For those whose breathlessness is induced or worsened by lifestyle choices such as smoking, this failure to report may be contributed to by the notion that chronic breathlessness and the associated suffering is in some way self-inflicted. A major reason why physicians may fail adequately to enquire about or explore chronic breathlessness and its treatments is because of a poor understanding of what can now be achieved in terms of symptomatic relief.

The last decade has seen major improvements in the evidence base for the safe and effective symptomatic reduction of chronic breathlessness where disease-modifying therapies have been exhausted. ${ }^{4}$ Pharmacologically, the evidence is that regular low-dose sustained release oral morphine (up to $30 \mathrm{mg}$ oral morphine $/ 24 \mathrm{~h}$ ) provides symptomatic relief safely, and that this benefit is sustained for many people over long periods of time. ${ }^{5} 6$ Recently, this improved evidence base has been reflected in seminal statements from a number of professional bodies including the American College of Chest Physicians, the American Thoracic Society and the Canadian Respiratory Society. ${ }^{7-9}$ These statements remove equivocation, with advice that '... opioids should be dosed and titrated for relief of dyspnoea in the individual patient ...' with chronic refractory breathlessness. $^{8}$

Failure to enquire about, assess and properly treat chronic refractory breathlessness with opioids as outlined in specialist clinical guidelines is now substandard medical care and is also a breach of clinicians' ethical and legal duties to the patient. Omitting opioids from the treatment of chronic breathlessness breaches all four principles of modern bioethics: beneficence-the duty to do good by relieving suffering; non-maleficence-the duty not to cause unnecessary suffering and harm; justice - since people with chronic refractory breathlessness are just as entitled to treatment using the best available evidence; and autonomy-undertreated breathlessness compromises a person's capacity to self-determination. Legally, symptomatic treatment of chronic refractory breathlessness with regular low-dose opioids should now be considered the standard of care, while the failure to do so could be considered a breach of one's duty to the patient and therefore negligent.

In addition to being a breach of professional, ethical and legal duties, failure to treat chronic 
refractory breathlessness adequately should be viewed as a breach of human rights. Adequate pain control through access to pain relief is now accepted as a human right, ${ }^{10}{ }^{11}$ and the symptomatic treatment of chronic refractory breathlessness should be seen in exactly the same way.

Pain and breathlessness are symptoms with similar characteristics in that substantial numbers of patients live for years or decades with these symptoms, physical and mental functioning are often both greatly impaired, and there are significant social and economic ramifications. People who experience chronic pain or breathlessness often fail to report its presence and the degree of the ensuing impairment, making it crucial that clinicians are properly educated in seeking out the presence of the symptom and assessing its total impact on the person.

As with pain, opioids are the pharmacological therapy with the strongest evidence base. However, the doses of opioids used for chronic refractory breathlessness are very low $(\leq 30 \mathrm{mg}$ oral morphine $/ 24 \mathrm{~h}$ ), yet the same barriers that restrict access to opioids for pain are evident. Many clinicians are convinced that using opioids in patients with respiratory compromise is an unacceptable risk, despite the absence to date of any case reports in prospective studies of respiratory depression when low-dose regular opioids are used. To redress this will require a strong commitment to educating current practitioners for whom this is a substantial change, and as the next generation is educated. In terms of political and legal barriers, fears of misuse, addiction and illicit diversion that have resulted in the severe restriction of opioid availability and therefore the suboptimal use of opioids for pain will be magnified as clinicians start to prescribe regular low-dose opioids for chronic refractory breathlessness.

Why is it important to frame the treatment and relief of chronic refractory breathlessness as a human right? Doing so would raise the profile of chronic refractory breathlessness in the minds of many patients and their clinicians as a symptom that can be significantly improved with pharmacological treatments such as opioids, and thus decrease the consequent suffering. It would also add a sense of urgency, which currently does not exist, to the importance of educating existing and future clinicians regarding the alleviation of chronic refractory breathlessness and the role of opioids. Finally, if freedom from chronic refractory breathlessness is an integral part of each person's right to health, it would add political pressure to improving access to opioids for chronic refractory breathlessness at the same time that its availability for pain is being systematically improved, particularly as local bureaucracies rather than cost are the major impediment to availability.

The International Covenant on Economic, Social and Cultural Rights (ICESCR) recognises 'the right of everyone to the enjoyment of the highest attainable standard of physical and mental health ${ }^{, 12}$ and, in theory, signatories are obliged to provide access to supportive and palliative care including necessary medication. An argument potentially exists that the control of every symptom should be considered a human right. However, the priority effort must be in proportion to the suffering experienced, and the prevalence, severity and chronicity of pain and breathlessness put them in a class of their own. They therefore demand particular emphasis in policy and practice.

Contributors DCC and DNK were responsible for the conception of the paper. DCC, DNK and APA contributed equally to the writing and final approval of the paper.

Competing interests DCC has received an unrestricted grant from Mundipharma for clinical research. APA has received research funding from the National Institute of Nursing Research, National Cancer Institute, Agency for Healthcare Research and Quality, DARA, Celgene, Helsinn, Dendreon and Pfizer; these funds are all distributed to Duke University Medical Center to support research including salary support for APA. Pending industry funded projects include: GlaxoSmithKline, Genentech, Bristol Myers Squibb, Insys and Kanglaite. In the last 2 years APA has had nominal consulting agreements with or received honoraria ( $<\$ 10000$ annually) from Novartis, Bristol Myers Squibb and Pfizer. Further consulting with Bristol Meyers Squibb is pending in 2013 for role as Co-Chair of a Scientific Advisory Committee. She has a paid leadership role with the American Academy of Hospice and Palliative Medicine (President) and has corporate leadership responsibility in Advoset (an education company that has a contract with Novartis) and Orange Leaf Associates LLC (an IT development company).

Provenance and peer review Not commissioned; internally peer reviewed.

\section{REFERENCES}

1 Currow DC, Plummer JL, Crockett A, et al. A community population survey of prevalence and severity of dyspnea in adults. J Pain Symptom Manage 2009:38:533-45.

2 Johnson MJ, Bowden JA, Abernethy AP, et al. To what causes do people attribute their chronic breathlessness? A population survey. J Palliat Med 2012;15:744-50.

3 Skilbeck J, Mott L, Page $\mathrm{H}$, et al. Palliative care in chronic obstructive airways disease: a needs assessment. Palliat Med 1998;12:245-54

4 Johnson MJ, Abernethy AP, Currow DC. Evidence-based management of chronic dyspnoea. Br J Gen Pract 2013;63:609-10.

5 Abernethy AP, Currow DC, Frith $\mathrm{P}$, et al. Randomised, double blind, placebo controlled crossover trial of sustained release morphine for the management of refractory dyspnoea. BMJ 2003;327:523-8.

6 Currow DC, Wheeler JL, Abernethy AP. International perspective: outcomes of palliative oncology. Semin Oncol 2011;38:343-50.

7 Marciniuk DD, Goodridge D, Hernandez P, et al. Managing dyspnea in patients with advanced chronic obstructive pulmonary disease: a Canadian Thoracic Society clinical practice guideline. Can Respir J 2011;18:69-78.

8 Mahler DA, Selecky PA, Harrod CG, et al. American College of Chest Physicians consensus statement on the management of dyspnea in patients with advanced lung or heart disease. Chest 2010;137:674-91.

9 Parshall MB, Schwartzstein RM, Adams L, et al. An official American Thoracic Society statement: update on the mechanisms, assessment, and management of dyspnea. Am J Respir Crit Care Med 2012;185:435-52.

10 Brennan F, Carr DB, Cousins M. Pain management: a fundamental human right. Anesth Analg 2007;105:205-21.

11 Lohman D, Schleifer $\mathrm{R}$, Amon JJ. Access to pain treatment as a human right. BMC Med 2010;8:8.

12 UN General Assembly. International Covenant on Economic, Social and Cultural Rights, 16 December 1966, United Nations, Treaty Series, Volume 993, p 3. http:// www.refworld.org/docid/3ae6b36c0.html. 